\title{
The History of Our World: The Hardcore Continuum Debate
}

\section{SIMON REYNOLDS}

Early in 2009, I became embroiled in a vigorous and at times heated debate about the retroactive validity and future viability of a concept I came up with a decade earlier: the "hardcore continuum". For a succinct explanation of what the term refers to and the background to the concept's emergence, check this piece in The Wire $<$ www.thewire.co.uk/articles/2009/>; and for a much longer and more detailed account from me, check this: <energyflashbysimonreynolds.blogspot.com/2009/02/ hardcore-continuum-or-theory-and-its.html >

At Dancecult's invitation, I am returning to historicize the concept and pinpoint what it refers to. I'll also attempt to historicize the controversy itself and account for some of the heat of the exchanges.

I want to start by taking slight issue with a comment of my esteemed colleague (and good friend) Mark Fisher in the first of this journal's commentaries on the hardcore continuum debate last issue. He characterized the approach I took in my talk at FACT in Liverpoool February 2009 (which if it didn't catalyze the pro- and antihardcore continuum debate, certainly raised it to a new pitch of intensity) as involving a strategic retreat from theory, which he regarded as a mistake. I take issue with this characterization. There's been no retreat from theorizing towards the empirical: there has actually been, on my part, a consistency of approach. My theorizing about the hardcore continuum, including the coinage of the term itself, emerged from field research, in the sense that it was the byproduct of a long period of extensive scenereporting as a working music journalist of, combined with years of intense involvement as a fan in, the subculture. On the one hand, I was interviewing people involved in the scene, writing genre overviews, reviewing albums and compilations and DJ performances, doing round-ups of new 12-inch releases. On the other hand, I was dancing at raves and clubs, going down the record store on a weekly basis to buy new tracks, tuning in to pirate radio stations and taping their broadcasts on the occasions I was in London, and then, when I was back in New York, importuning my London friends to tape the shows and mail them to me. But I didn't really separate these activities, or consciously think of it as a form of participant-observer research: it was all one unified front of passion and evangelism. After coining the concept in 1999, its theorization as it developed through the Noughties continued to be inseparable from the activities of journalism and fandom (with blogging falling somewhere in between the two), especially in the first half of the decade with grime, which was especially thought-provoking and fanaticism-catalyzing.

http://www.youtube.com/watch?v=Nwfikgc6vs4

Lethal B featuring Fumin, D Double E, Nappa, Jamakabi, Neeko, Flow Dan, Ozzi B, Forcer, Demon \& HotShot, "Pow (Forward)", 2004 
Now I'm sure there are sound philosophical reasons for worrying away at the concept of the empirical, but I'm happily ignorant of them and for me it's always been the case that the two activities - field research and theoretical speculation - are inseparable.

Fisher also made some interesting points about the abstract reality of the hardcore continuum, making an analogy with the credit crunch and the recession: "The reality of the hardcore continuum is not of the order of a physical fact, but of an abstract entity. The notion of an abstract-real materiality may cause commonsense to recoil, yet a moment's reflection makes us realise, not only that abstract entities are real, but that there is nothing more real than them". As Fisher suggests, the "abstractreal" is possibly a difficult concept for most people to grasp. "Abstract" seems like it is the opposite of "concrete", and most people would place "reality" on the side of the concrete, the material, the experiential. But I think Fisher is on to something here. One place to recognise where this apparent empirical/theoretical clash is resolved is within history itself. They are plenty of examples of social and economic phenomena that are real and material but are not necessarily consciously apprehended in their systemic totality by the subjects who constitute and sustain them. And it strikes me that the hardcore continuum could be usefully seen as a system: a structure, a set of relations, a means of musical production. Although vastly smaller in scale and significance, it is analogous to socioeconomic and cultural-political formations such as imperialism, slavery, or manorialism (a.k.a. serfdom). All three of those things are at the same time historically existent entities and sites of theorization on the part of scholars.

No one would deny the existence of the European empires (British, French, Belgian, etc). At the same time there are numerous theories of imperialism, a fierce and long-running debate across a spectrum from Marxist analysis and anti-colonialist critiques to revisionist defenders. Now, the empires actually called themselves empires. With manorialism/serfdom, I don't think people in that system necessarily conceived of their lived reality as a system, in the same way that it's unlikely that any peasant declared, a la Monty Python's Holy Grail, "Now we see the violence inherent in the system!". But that doesn't mean that the systemicity didn't exist, or that there wasn't violence inherent in the system. Manorialism/serfdom, then, I think makes a particularly good analogy with the hardcore continuum: these are specialist terms, used retrospectively by historians rather than the actual inhabitants of what they describe, for systems that, nonetheless, existed (in the case of manorialism, taking the form of relations of fealty, property rights, division of land, farming methods, inheri-tance customs, etc) as both an abstract structure and a lived reality. The manorial system had variations regionally and across Europe; it evolved through time, rising and declining. It also co-existed with other kinds of socioeconomic activity and social relations, like the guild system and merchant trade, which evolved into the early forms of capitalism, and so forth. But the manorial or seigneurial system lingered in vestigial form, for a long time after its prime.

What is the systemic "core" of the hardcore continuum then? It's a particular set of relations based around pirate radio, dubplates, raves and rave-style clubs, along with certain kinds of music-making technology. The system coalesced gradually, enjoyed a prime, but now may well be fading away or disintegrating. I've argued that the hardcore continuum is a UK adaption of the Jamaican system. Instead of sound systems mutating into raves or clubs (the obvious adaption, you might have thought), I think what happened was that pirate radio stations took the place of sound systems: they were sounds on the air. Another major UK mutation of the Jamaican approach was 
with dubplates. In Jamaica and in the direct UK transplant of the Jamaican approach in the form of UK reggae systems, dubplate specials were the unique property of a single sound system. In the UK hardcore raves scene, a more complicated system developed because of the guest DJ circuit that sprang up from the late Eighties onwards as a result of house music. This meant that DJs, instead of being tied to a sound system or a club residency, became independent operators playing at different raves and clubs. Dubplates then evolved into a kind of patronage system or symbiotic exchange relationship between a DJ and a loose stable of producers. Sometimes, with a really powerful DJ, that becomes an exclusive relationship (Grooverider's "boys" would give only him their tracks; he would choose which ones out of many offered to make up as dubplates). Sometimes it would be semi-exclusive (a name producer giving dubs to a select group of DJs). And of course you had DJs who were producers themselves and cut dubs of their own music.

Nowadays, as has been noted by some commentators, this particular system is eroding as terrestrial broadcast pirate radio wanes in importance, while DJs increasingly move to digital formats and make a name for themselves with give-away mixes and podcasts on the web. Similar to the emergence of merchant trade and early capitalism in parallel with a waning feudalism, a new system, fully integrated with the web, eclipses the older one.

The fact that new modes of transmission and dissemination are emerging, though, does not somehow retroactively erase the existence of the preceding and formerly dominant system (which is the conclusion that some seem eager to jump to). It also seems likely that pirate radio will continue as a residual force for a good while yet, servicing local populations in particular urban areas.

History is not a closed book, but it is not a completely open one either. Interpretations are constantly changing; new information comes to light. For instance, when I studied history in the early Eighties, I specialized in American history, including the Civil War, slavery and Reconstruction. At that point, relatively recent research had significantly expanded and altered the understanding of slavery as an institution and practice. As it turned out, the plantation system - everybody's received idea of the Deep South (the big house, the labor and cultural division between house servants and the field workers, etc) - was an incomplete picture of slavery. Many slaves were actually owned by small farmers: a few slaves, sometimes just one, often lived in intimate proximity with their masters, who didn't comport themselves as leisurely aristocrats in some Walter Scott-type Dixie fantasy, but lived modest, hardworking lives.

But there are limits to perspectivalism. Slavery existed, imperialism existed, the manorial system existed. The hardcore continuum is an historical phenomenon of that kind.

When you take into consideration the systemic infrastructure that underlies the hardcore continuum's sonic evolution, it enables you to see how the macro-scene has remained coherent even when there's been drastic mutations in sound, huge leaps or drops in tempo, significant differences in "vibe" between various micro-scenes within the larger continuum. It also enables you to see past superficial similarities of sound between hardcore continuum genres and others that are not, in any real historical sense, part of the continuum.

A good example here is Big Beat. Now this is a genre I happen to like a lot. In its prime, it produced some fantastic records and some of the best dancing nights of my life. I'll always be fond of, and ready to defend, Fatboy Slim, Chemical Brothers, and various other figures in that area. Now Big Beat actually had some resemblances to the 
breakbeat hardcore sound of the early Nineties, both sonically and in terms of attitude: the collision of hip hop and house, the riffy-ness, the hell-for-leather drugginess. But from an historical perspective, there is no link between Big Beat and the hardcore continuum. All those Big Beat people came out of the Balearic/"Madchester"/indiedance lineage. Big Beat was also organized around a completely different systemic infrastructure to the hardcore continuum. There were no Big Beat pirate stations. Big Beat was much more intimately connected with the mainstream record industry, there were relationships to certain major-league indie-rock bands (which, as Britpop took off, became the biggest rock bands in the land), there was the connection with the power nexus of Heavenly (the record label/publicity/management organization, who launched the key early Big Beat club, the Heavenly Social, in 1994). Big Beat was based around a different circuit of clubs and had a markedly different audience composition (much more white and middle class). There were different rituals. For instance, the role of the MC in hardcore continuum genres was not paralleled in Big Beat, nor was the rewind as derived from Jamaican sound system culture, and as far as I'm aware, dubplates were not part of Big Beat.

\section{http://www.youtube.com/watch?v=g04lgcOijYg}

The Chemical Brothers, "Loops of Fury", 1996

http://www.youtube.com/watch?v=s5EUpPiXp-4

Fatboy Slim, "Song For Lindy", 1997

Now, as I say, I have great affection for Big Beat as a moment. So it is no slight on Big Beat but just simple historical accuracy to say that it isn't part of the continuum narrative. However, I would also venture to suggest that the reason Big Beat didn't lead to anything much (in terms of subsequent genres or a legacy beyond itself) is related to the fact that it wasn't based around as radical and fertile a systemic structure as the econo-cultural engine that sustained hardcore/jungle/UK garage/grime/dubstep.

http://www.youtube.com/watch?v=QJFUKl1Ehpk

Phuture Assassins, "Roots 'N Future", 1992

If I was to attempt to boil the hardcore continuum debate down to a single exchange, it would go like this:

Anti-Continuum: "You've mistaken the model for reality".

Pro-Continuum: "On the contrary, you've mistaken the reality for a model".

Unpacking that last bit: the antipathy felt by some to the theory (and in a few cases, to the theory's prominent exponents) has undergone a slippage, becoming a wishful hostility to the thing itself... a desire to wish away the historical reality of the connections between these genres: the family tree that runs hardcore/jungle /UK garage/grime/dubstep/funky.

As a result, the whole debate about the continuum has been framed incorrectly. The doubter's stance is: "do we still need this model, this way of looking at the recent musical past?" (The implication being that it's optional, just one choice of prism from many). The right question is: "what actually happened back then?" From there, the 
next questions are "what did it mean?" and "what, if anything, can we learn from it, in terms of how music and culture works?"

I promised to historicize the controversy, and to account for the heat of the argument. The prominent participants have their own angles and motivations, I'm sure, but on a general level my sense is that there is a generational aspect to the dispute. And appropriately enough, this revolves around the issue of history itself. There are three facets to this.

\section{History felt as burden/obstacle/impediment/shackle.}

The continuum has been "a game of two halves" and the storied glory of the first half of the match (the Nineties) seems increasingly to be something from which many younger participants in this music culture no longer draw nourishment, but would much rather like to shrug off (and if you happen to be a historian of that History you might well come to be associated with this "thing in the way").

\section{The desire to turn the page in the book of History, start a fresh chapter.}

This is understandable and, in fact, something I feel myself. The strange and slightly morbid attachment that some young people have to genres like hip hop or house that have been around for three decades mystifies me (why aren't they impatient to just sweep them aside?). While I empathize with the "turn the page”/"let's push things forward" impulse, simple impatience won't do it, not on its own. History will "move on" when it is ready to. Totally new and unforeseen sounds and subcultures have emerged in the past - jazz, rock ' $n$ ' roll, disco, reggae, hip hop, rave, to name only the most obvious - and the previous formations of popular music have simply fallen away (without ever actually disappearing or dying out completely). But that happens through processes that are anonymous and collective, rather than willed and criticdriven.

\section{Hostility to historical thinking, to narrativization and grand récits per se.}

Here I'm getting into a more speculative area, but the impression I have is that for many of the younger generation, historical thinking has grown foreign to the way they relate to music. The musical past has become spatialized: sounds from all the different eras of history are equally available to us, and, furthermore, they are just as available as the music of the present. In one sense the past is totally present, all of it, in a way that it's never been before. But historical depth drops out, the original context or meaning of the music becomes steadily more irrelevant; music is just material to redeploy. If you've grown up, as anyone under the age of 30 really has, with a relationship to music based around total access, superabundance, and the erosion of a sense of sounds having placement within an historical or temporal scheme, then thinking about music in terms of causal links and development through time becomes ever more alien to your consciousness. The idea that jungle led to UK garage, or 2 step evolved into grime (so crucial to those, like me, who lived through these transformations, thrilled to them and puzzled over them in real-time), becomes both irrecoverable and simply irrelevant to their practice as DJs, or producers or consumers. Leaps across the genrescape, through affinity of sound, seem more persuasive, even if there's no actual historical connection there. 
http://www.youtube.com/watch?v=h32WKef1UzM

Micky Finn \& MC Prince at AWOL, Paradise Club, London 1992

http://www.youtube.com/watch?v=jFCd8X1mtkY

AWOL, A Way of Life Live, Ministry of Sound, London 1995

Why should anyone care about history? Why does it matter? For most people who are fans and participants in the dance culture, it doesn't particularly. But I think if you actually have any interest in understanding how these scenes work and grow, then attempting to establish what actually happened, the how and the why, is invaluable. And that involves historical thinking. This is not about history as a monument, or a canon: something imposing, an imposition by the past upon the present. It is simply the acknowledgement of a rich area of lived culture that actually existed and that extended beyond the music to encompass how it was used, what kind of behavior and relations and social spaces the music made possible. It's not just about the abstract, quasi-cybernetic model of the continuum as a machinery of "scenius" (Brian Eno's term for anonymous and collectivized forms of creativity) but the scene-ness of it all: pirate radio, the business/micro-capitalist aspects of the culture, the dances, the slang, the MC catchphrases. It's about the "A Way of Life" aspect (AWOL being the name of a famous jungle club). All those individual lives that transected the hardcore continuum, contributed to it, and were changed by it. A parallel here might be E. P. Thompson or Fernand Braudel, their different initiatives to enlarge the proper domain of history to include everyday life, not just battles and elections and the succession of kings. In pop music terms, the equivalent would be focusing not just on Top Ten hits and megastar careers, but a minoritarian history, attending to the narratives of semipopular music and downright unpopular music. It's about doing justice to what in the global sense of pop - even in the global sense of dance music, to be honest - was a backwater. This is perhaps a good point to register my bemusement at the fact that certain commentators seem to regard the "hardcore continuum" as some sort of dominant narrative oppressing the minds of modern youth. Actually, it's pretty marginal, looming large in the heads of a really small number of people. It's the "History of Our World", to borrow the title of a 1994 jungle compilation. But that "us" and that "world" always were and still remain distinctly compact entities.

\section{Afternote}

Particular relationships to history - to the hardcore continuum's own history - can be seen in the way the main continuum genres of the last five years have developed strategies of renewal for the music.

\section{Strategy 1: Keeping the Faith/Renewal Through Recombination}

Dubstep is what happened when a degree of self-consciousness about its own history seeped into the hardcore continuum. In the last few years, though, dubstep has been recharged by an influx of ignorance, a new breed of historical know-nothing fans, and this suggests that something new may come out of it: the wobble sound (considered by cognoscenti to be a bastardization of true dubstep) has become a genuine hardcore, with a revived association with drug abuse and rowdy behavior. Meanwhile the "true" dubstep fans - history boys and scholars of the continuum all - have veered off in a variety of post-dubstep directions, many of which involve reactivating Nineties vibes. 
Kryptic Minds, for instance, resurrect the era of Photek/Source Direct/Hidden Agenda, that cinematic, atmospheric, exquisitely produced apex of drum ' $n$ ' bass in the second half of the Nineties. Elsewhere you have dubsteppers who are influenced by the dub-techno sounds of Basic Channel/Chain Reaction/Pole, and so forth.

http://www.youtube.com/watch?v=Q1EyR27fvGc

Coki, “Spongebob", 2007

http://www.youtube.com/watch?v=8mHhaZX0ImU

Caspa \& the Others, "Well 'Ard", 2008

versus

http://www.youtube.com/watch?v=ChC4ZU2QrSM

Kryptic Minds, “Generation Dub”, 2009

http://www.youtube.com/watch?v=-EFA03rfQOI

Martyn, "Little Things", 2009

\section{Strategy 2: Drawing in New Material from "Outside"}

Funky house, or as people now prefer to call it, funky, is a classic example of the strategy of assimilating fresh input from genres outside the hardcore continuum's traditional range of sources (reggae, hip hop, techno, etc). Funky draws on ideas and flavors from Masters at Work, DJ Gregory, Afro house, soca, broken beats, tribal house, and more. So much stuff from outside has entered the mix that the music almost feels like it's becoming something else altogether, a vibe different from anything we've heard from the hardcore continuum before. Yet, of all the sounds of the last half-decade, funky is the one that remains closest to the infrastructural matrix, the systemic core, of the continuum (i.e. the pirates, the London demographic, etc). And the assimilation of outside material to enable the scene to move past a deadlock (grime) is itself an historical echo of the move made by speed garage and 2step in the late Nineties (drawing on New York garage, Todd Edwards's vocal cut-ups, Timbaland-style R\&B) in response to the apocalyptic noise of techstep drum'n'bass. Like funky, this was a move back towards pleasure and pleasantness, celebration and sexiness.

http://www.youtube.com/watch?v=T_V9chwSWKs

Donaeo, "Party Hard", 2009

http://www.youtube.com/watch?v=HsHqn7GgWfg

Kris Baya, "Heartbreaker (Ill Blu Mix)", 2009

http://www.youtube.com/watch?v=QJGEIN47MYM

DVA (a.k.a. Scatcha a.k.a. Soule Power), "Natty”, 2010

\section{Strategy 3: Lines of Flight}

Here I'm talking primarily about the "wonky" operatives who are clearly coming out of dubstep (such as Zomby) and grime (such as Joker). Sensing impending deadlock, impelled by the artistic instinct to have somewhere to go and the desire not to be bored, they've located lines of flight that extend across space (to American glitch hop and spacefunk), across genre (connecting with "the boom bap continuum" of Dilla, Flying Lotus, et al, or to UK beat digger types like Lucky Me/Hudson Mohawke/ Rustie et al) and back through time (to G-funk, Eighties cartoon funk such as Cameo, 
videogame music). This relates to the notion I broached above of music history having become spatialized, splayed out like an atemporal smorgasbord. The question raised by this all-you-can-eat buffet, which tempts producers to stuff their music with too many influences and rich flavours, is whether genre-icity and (in a club situation) coherency of vibe can survive such bounty. For genres are defined by their exclusions and selflimitations as much by their positive choices. A music that tries to be everything risks becoming nothing in particular. So far, the artists in this emerging zone-withoutborders who have fared the best are those with some kind of relationship to the hardcore continuum (Zomby, Joker) whereas some of those who don't have that background have come a cropper (Hudson Mohawke with his glutted/clotted debacle Butter). Coincidence? I doubt it.

http://www.youtube.com/watch?v=G-BEqvrS24s

Zomby, "Kaliko", 2008

http://www.youtube.com/watch?v=zzHOdfSHZgs

Joker, “Digidesign”, 2009

http://www.youtube.com/watch?v=IfH6NwpjSGA

Hudson Mohawke, "Butter Snips" (sampler/megamix from the album Butter), 2009

\section{Author Biography}

Simon Reynolds is the author of Energy Flash: A Journey Through Rave Music and Dance Culture (a.k.a. Generation Ecstasy), originally published in 1998 and reissued in an expanded and updated edition in 2008 by Picador. He maintains a number of blogs, including Energy Flash http://energyflashbysimonreynolds.blogspot.com/ and Blissblog http://blissout.blogspot.com/ 